\title{
Qualidade física, fisiológica e sanitária de sementes de milho crioulo produzidas no norte de Minas Gerais
}

\author{
Physical, physiological and seed health qualities of maize landrace seeds produced on northern \\ Minas Gerais, Brazil
}

\begin{abstract}
Hugo Cesar Rodrigues Moreira Catão ${ }^{\mathrm{I}}$ Flaviane Malaquias Costa $^{\mathrm{II}}$ Samuel Vasconcelos Valadares ${ }^{\mathrm{I}}$ Emuriela da Rocha Dourado ${ }^{I}$ Delacyr da Silva Brandão Junior ${ }^{\mathrm{I}}$ Nilza de Lima Pereira Sales ${ }^{\mathrm{I}}$
\end{abstract}

\section{RESUMO}

Os objetivos deste trabalho foram avaliar a qualidade física, fisiológica e sanitária de sementes de 17 variedades de milho crioulo antes e após armazenagem em garrafas PET e comparar os resultados aos padrões já estabelecidos para comercialização de cultivares comerciais de milho. Foram realizados os testes de pureza física, retenção de peneiras, massa de 1000 sementes, grau de umidade, germinação, emergência em canteiro, índices de velocidade de germinação e emergência das sementes, além de exame de sementes infestadas. Pelos resultados obtidos, é possível concluir que as sementes de milho crioulo das diferentes variedades apresentam alta porcentagem de pureza física e germinação mesmo após o armazenamento, com valores acima dos padrões mínimos exigidos para comercialização de sementes de milho (98 e 85\%, respectivamente). O grau de umidade das sementes das diferentes variedades de milho crioulo antes e após o armazenamento permaneceu abaixo de $13 \%$, destacando-se a aptidão da região norte de Minas Gerais para a produção e conservação de sementes de qualidade. Três variedades apresentaram porcentagem de infestação superior ao padrão máximo recomendado (3\%), sendo, portanto, necessário aprimorar o controle de pragas de grãos armazenados. São necessárias melhorias para uniformização de classificação das sementes por peneiras, já que as amostras de três variedades não alcançaram o padrão mínimo de $94 \%$ em uma mesma peneira, exigido pela legislação.

Palavras-chave: Zea mays, conservação, variedades tradicionais, armazenamento.

\section{ABSTRACT}

The objective of this research was to evaluate the physical, physiological and sanitary quality of corn seeds of 17

\begin{abstract}
maize varieties (landraces) before and after storage in PET bottles. The seeds were submitted to the following tests: physical purity, retention on sieves, weight of 1000 seeds, germination, seed moisture content, emergence in flowerbed, infested seed exam and seed health (deep-freezing method). Germination and emergence velocity index were determined. Maize landraces seeds of different varieties presented a great percentage of physical purity and germination, which were over the minimum standards values required for commercialization of corn seeds (98 and 85\%, respectively), even after storage. Seed moisture content remained below $13 \%$ before and after storage, standing out the potential of Nothern Minas Gerais for production and conservation of high-quality seeds. Three varieties presented infestation higher than the maximum values accepted for corn seeds commercialization (3\%), indicating the need of better pests control during storage. Samples of three varieties have not reached satisfy standard values of retention on the same sieve (94\%), indicating the need of better standardization on size classification of some seed lots.
\end{abstract}

Key words: Zea mays, seeds conservation, traditional varieties, storage.

\section{INTRODUÇÃO}

A semente é um dos insumos mais importantes na agricultura, constituindo-se em fator determinante do sucesso ou fracasso dos cultivos (COSTA \& CAMPOS, 1997). As sementes de variedades locais são consideradas como componentes da agrobiodiversidade, por constituírem inestimável valor para as populações tradicionais.

'Universidade Federal de Minas Gerais (UFMG), 39270-000, Belo Horizonte, MG, Brasil. E-mail: hugocatao@yahoo.com.br. Autor para correspondência.

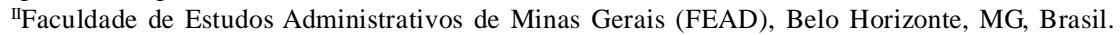


A partir da década de 50 ocorreram muitas transformações na agricultura, entre as quais, o melhoramento genético foi, talvez, o que mais afetou a vida dos agricultores (MENEGUETTI et al., 2002). As variedades locais ou tradicionais foram gradativamente substituídas por materiais melhorados, com a adoção de pacotes tecnológicos para subsidiar as maiores produtividades então obtidas. Por razões diversas, muitos agricultores ainda utilizam variedades crioulas de milho, sendo uma importante forma de conservação desses materiais, de grande variabilidade genética, sendo importante para estratégias de conservação da agrobiodiversidade, assim como para o melhoramento genético da espécie.

Em agosto de 2003, entrou em vigor, no Brasil, a nova lei de sementes (Lei n.10.711/03), que estabelece o sistema nacional de sementes e mudas, cujo objetivo é garantir a identidade e a qualidade do material de multiplicação e de reprodução vegetal produzido, comercializado e utilizado em todo país. Por meio dessa legislação, as sementes crioulas passam a ser oficialmente reconhecidas. Entretanto, a lei não regulamenta o controle de qualidade do material crioulo, ao contrário das cultivares comerciais existentes no mercado de sementes (CAMPOS et al., 2006).

A utilização de sementes de qualidade comprovada constitui-se em fator preponderante para o estabelecimento das lavouras, possibilitando maiores produções. A armazenabilidade das sementes é influenciada pela qualidade inicial dos lotes, bem como pelas condições de armazenamento. Os problemas de armazenamento estão entre os mais comuns que entravam o desenvolvimento dos programas de sementes nos países menos desenvolvidos (AZEVEDO, 2003). As estratégias de conservação, uso, multiplicação e comercialização das sementes crioulas no norte de Minas Gerais se traduzem em ações, como acompanhamento aos campos de produção de sementes, valorização dos bancos de sementes comunitários e testes para o controle de qualidade das sementes produzidas em comunidades rurais, de maneira que os produtores tenham mais autonomia. Visando a alcançar o máximo de qualidade nas sementes produzidas, o produtor deve desenvolver um programa com normas de controle, que se baseia na identificação e avaliação dos problemas de qualidade, em ações preventivas que garantam a manutenção da qualidade, no monitoramento dessa qualidade ao longo do processo produtivo e na adoção de procedimentos que visem a corrigir erros operacionais. Desta forma, os objetivos deste trabalho foram avaliar a qualidade física, fisiológica e sanitária de sementes de diferentes variedades de milho crioulo produzidas, beneficiadas e armazenadas pelos próprios agricultores e confrontar a conformidade do processo aos padrões estabelecidos para cultivares de milho comerciais.

\section{MATERIAL E MÉTODOS}

A presente pesquisa foi conduzida no Laboratório de Análise de Sementes (LAS) do Instituto de Ciências Agrárias da Universidade Federal de Minas Gerais (ICA/UFMG). Foram utilizadas sementes de milho de 17 variedades crioulas provenientes do município de Porteirinha, Minas Gerais (MG), processadas manualmente, da safra 2006/2007. Os testes para avaliações das qualidades físicas e fisiológicas foram realizados logo após a colheita, no período de maio a junho de 2007, e repetidos no período de novembro a dezembro de 2007, após o armazenamento em garrafas PET (embalagem de polietileno tereftalato). Para a avaliação da qualidade física, foram realizados testes de pureza física, retenção de peneiras, massa de 1000 sementes e grau de umidade, conforme prescrições das Regras para Análises de Sementes-RAS (BRASIL, 2009).

Na determinação da pureza física (\%), amostras de cada variedade foram pesadas e separadas nos diferentes componentes presentes (sementes puras, outras sementes e material inerte). $\mathrm{Na}$ determinação da uniformidade de classificação das sementes (teste de retenção de peneiras), foram utilizadas duas subamostras de 300 gramas de sementes puras de milho, submetidas à agitação durante um minuto, em peneiras manuais. Em seguida, estas foram pesadas, obtendo-se o percentual de retenção em cada peneira. Pesaram-se oito repetições de 100 sementes e, a partir dos resultados obtidos, calculou-se o peso de 1000 sementes. A determinação do grau de umidade foi realizada pelo método da estufa a $105 \pm 3^{\circ} \mathrm{C}$, por um período de 24 horas, sendo utilizadas duas repetições para cada variedade.

A avaliação da qualidade fisiológica foi realizada por meio de testes de viabilidade e vigor (germinação e emergência em canteiro). O teste de germinação foi conduzido em germinador Mangelsdorf, a $25^{\circ} \mathrm{C}$, e realizado conforme recomendações das Regras para Análises de Sementes-RAS (BRASIL, 2009), sendo cada tratamento composto por quatro repetições de 25 sementes semeadas em papel germiteste no sistema rolo, umedecidas com água na quantidade de 2,5 vezes o peso do papel. Foram realizadas contagens diárias de emissão de radícula, para avaliação do índice de velocidade de germinação (IVG). Aos quatro e sete dias após a semeadura, foi avaliado o número de plântulas normais para primeira contagem e percentagem de germinação, respectivamente. 
No teste de envelhecimento acelerado, foram utilizadas caixas gerbox com $40 \mathrm{ml}$ de água, onde as sementes foram distribuídas uniformemente sobre uma tela metálica. As caixas foram mantidas em câmara de envelhecimento tipo B.O.D, a $42^{\circ} \mathrm{C}$, durante 96 horas. Após esse período, as sementes foram colocadas para germinar a $25^{\circ} \mathrm{C}$ e avaliadas sete dias após a semeadura (KIKUTI et al., 2003).

O teste de emergência em canteiro foi feito com semeadura de 50 sementes em quatro repetições, espaçadas $5 \times 5 \mathrm{~cm}$, em canteiros contendo areia como substrato. Ao longo de 10 dias, foi avaliado o número de plântulas emergidas para calcular o índice de velocidade de emergência (IVE). A emergência final foi avaliada com contagem aos 21 dias após a semeadura. Para o cálculo do IVG e IVE, utilizou-se a fórmula sugerida por MAGUIRE (1962).

Para o exame de sementes infestadas, utilizaram-se duas repetições de 100 sementes por tratamento, sendo estas imersas em água por 48 horas e posteriormente seccionadas e avaliadas uma a uma, sendo consideradas sementes infestadas aquelas com a presença de ovo, larva, pupa, inseto adulto ou algum orifício no qual o inseto pode ter saído (BRASIL, 2009).

O delineamento experimental utilizado foi inteiramente casualizado, e os dados foram submetidos à análise de variância e aos testes de médias e ScottKnott, a 5\% de probabilidade, com exceção dos dados da pureza física. Os dados de percentagem foram transformados para $\mathrm{y}=\operatorname{arc} \operatorname{sen}(\sqrt{\mathrm{x} / 100})$.

\section{RESULTADOS E DISCUSSÕES}

Embora o beneficiamento de sementes convencionais de milho seja altamente especializado se comparado com o de outras grandes culturas (BAUDET \& MISRA, 1991), no processamento de variedades crioulas dessa mesma espécie, normalmente os agricultores utilizam tecnologias alternativas, com a utilização de pouco ou nenhum equipamento para beneficiamento.

As 17 variedades de milho crioulo avaliadas apresentaram porcentagem de pureza acima do mínimo exigido pelas normas de sementes (98\%) (Tabela 1), com ausência de propágulos de plantas daninhas, o que reflete a aplicabilidade dos métodos desenvolvidos pelos pequenos agricultores para a produção de sementes em suas condições de produção.

Foram observadas grandes variações quanto à massa de 1000 sementes (Tabela 1), certamente, devido à grande variabilidade entre os diferentes materiais. As variedades Amarelão e Asteca

Tabela 1 - Resultados dos testes de pureza (\%), umidade (\%) e massa de 1000 sementes (g) de milho crioulo antes e depois do período de armazenamento.

\begin{tabular}{lcccccc}
\hline & \multicolumn{2}{c}{ Pureza (\%) } & \multicolumn{2}{c}{ Umidade (\%) } & \multicolumn{2}{c}{ Massa de 1000 sementes (g) } \\
Variedades & $1^{\underline{a}}$ Avaliação & $2^{\underline{a}}$ Avaliação & $1^{\underline{a}}$ Avaliação & $2^{\underline{a}}$ Avaliação & $1^{\underline{a}}$ Avaliação & $2^{\underline{a}}$ Avaliação \\
\hline Amarelão & 100 & 99,98 & $11,56 \mathrm{aA}$ & $9,60 \mathrm{bB}$ & $385,25 \mathrm{aA}$ & $372,48 \mathrm{bB}$ \\
Vinhedo & 100 & 100 & $11,27 \mathrm{aA}$ & $10,95 \mathrm{aA}$ & $343,55 \mathrm{cA}$ & $346,6 \mathrm{~dB}$ \\
Santo & 99,9 & 100 & $10,87 \mathrm{aA}$ & $8,74 \mathrm{bB}$ & $289,93 \mathrm{fA}$ & $255,65 \mathrm{iB}$ \\
Asteca & 100 & 100 & $11,00 \mathrm{aA}$ & $11,49 \mathrm{aA}$ & $379,58 \mathrm{aA}$ & $366,09 \mathrm{bB}$ \\
B. Barra & 100 & 99,95 & $10,92 \mathrm{aA}$ & $10,55 \mathrm{aA}$ & $291,21 \mathrm{fB}$ & $301,98 \mathrm{gA}$ \\
Coruja & 99,95 & 99,91 & $11,43 \mathrm{aA}$ & $11,74 \mathrm{aA}$ & $362,38 \mathrm{bA}$ & $359,23 \mathrm{cA}$ \\
T. Doce & 100 & 99,98 & $11,64 \mathrm{aA}$ & $11,26 \mathrm{aA}$ & $255,91 \mathrm{gA}$ & $244,19 \mathrm{jB}$ \\
F. Rajado & 99,94 & 100 & $11,51 \mathrm{aA}$ & $11,58 \mathrm{aA}$ & $372,23 \mathrm{bB}$ & $382,66 \mathrm{aA}$ \\
C. Anão & 99,86 & 99,96 & $11,15 \mathrm{aA}$ & $11,09 \mathrm{aA}$ & $372,55 \mathrm{bA}$ & $336,35 \mathrm{eB}$ \\
Catingueiro & 99,96 & 99,59 & $11,48 \mathrm{aA}$ & $8,68 \mathrm{bB}$ & $372,04 \mathrm{bA}$ & $381,95 \mathrm{aA}$ \\
C. Crioulo & 99,99 & 99,61 & $10,88 \mathrm{aA}$ & $9,76 \mathrm{bB}$ & $324,83 \mathrm{dA}$ & $288,1 \mathrm{hB}$ \\
Caiçara & 100 & 100 & $11,88 \mathrm{aA}$ & $12,18 \mathrm{aA}$ & $316,38 \mathrm{dA}$ & $314,16 \mathrm{fA}$ \\
Amarelinho & 100 & 99,89 & $11,15 \mathrm{aA}$ & $10,51 \mathrm{aA}$ & $372,16 \mathrm{bA}$ & $288,46 \mathrm{hB}$ \\
Tio João & 99,91 & 99,97 & $10,48 \mathrm{aA}$ & $10,87 \mathrm{aA}$ & $323,08 \mathrm{dA}$ & $319,3 \mathrm{fA}$ \\
M. Amarelo & 100 & 99,5 & $11,92 \mathrm{aA}$ & $10,50 \mathrm{aB}$ & $368,2 \mathrm{bA}$ & $302,41 \mathrm{gB}$ \\
P. Vinhedo & 99,89 & 99,71 & $10,50 \mathrm{aA}$ & $11,02 \mathrm{aA}$ & $148,96 \mathrm{hA}$ & $114,1 \mathrm{kB}$ \\
F.Campo & 100 & 99,4 & $10,69 \mathrm{aA}$ & $11,02 \mathrm{aA}$ & $302,31 \mathrm{eB}$ & $313,93 \mathrm{fA}$ \\
CV (\%) & & & 2,35 & & 3,18 \\
\hline
\end{tabular}

*Médias não seguidas pela mesma letra minúscula, na coluna, e maiúscula para a época de avaliação diferem entre si pelo teste Scott-Knott e $\mathrm{F}$, respectivamente, a $5 \%$ de probabilidade. 
apresentaram as maiores massas, 385,3 e 379,6g, respectivamente, antes do período de armazenamento. Entretanto, após o armazenamento, as variedades Ferro Rajado e Catingueiro foram as que apresentaram maiores massas, 382,6 e 381,9g, respectivamente. Em determinadas situações, as maiores sementes podem não ser as mais vigorosas (CARVALHO \& NAKAGAWA, 2000). Todavia, a massa das sementes é uma variável no processo de produção, pois pode influenciar não somente o processo de semeadura, mas também a qualidade das sementes, além de ser um dos componentes do rendimento final (TRAVERSO, 2001). Há uma resistência por parte do agricultor na utilização das sementes redondas e daquelas de menor tamanho por suspeitarem que estas não germinam bem, além de apresentarem menor desempenho no campo. Entretanto, diversos trabalhos têm demonstrado a não interferência do tamanho da semente de milho em sua germinação e no seu vigor (MARTINELLI-SENEME, et al., 2001). Contudo, a classificação das sementes de milho por tamanho é um aspecto importante na comercialização e principalmente na semeadura (SATO \& CÍCERO, 1992).

No teste de Retenção de Peneiras (Tabela 2 ), antes da armazenagem, amostras de 15 variedades apresentaram retenção superior a $96 \%$ na peneira 22 , atendendo o mínimo de $94 \%$ em uma mesma classificação, exigido pela legislação. As amostras das variedades Tupiniquim Doce e Pipoqueiro Vinhedo não alcançaram esse valor mínimo exigido em uma mesma classificação, apresentando maior desuniformidade em relação às demais, (Peneiras - 22 / 92,29\%; 20 / 7,66\%; 18 / 0,04\% e Peneiras - 22 / 24,73\% ; 20 / 51,74\%; 18 / $23,52 \%$, antes e após a armazenagem respectivamente). Após o armazenamento, os valores de retenção de peneiras se comportaram de forma semelhante, com exceção da variedade Santo, que apresentou maior desuniformidade (Peneiras - 22 / 97,28\%; 20 / 2,72\% e Peneiras - 22 / 87, 29\%; $20 / 12,64 \%$; 18 / 0,08\%, na primeira e na segunda época, respectivamente). Esses resultados indicam a necessidade de melhorias na uniformização dos lotes de sementes, pois, de acordo com SCHUCH \& PESKE (2008), a uniformidade do tamanho e da forma de sementes de milho proporciona um menor número de falhas e duplos na linha de semeadura, o que melhora a plantabilidade destas.

A baixa umidade relativa do ar, característica da região norte de Minas Gerais (de acordo com Köeppen, o clima é denominado Aw - clima tropical de savana com inverno seco e verão chuvoso, também

Tabela 2 - Percentual de retenção em peneiras, emergência e índice de velocidade de emergência de sementes de milho crioulo em dois períodos de avaliação.

\begin{tabular}{|c|c|c|c|c|c|c|c|c|}
\hline \multirow[b]{2}{*}{ Variedades } & \multicolumn{4}{|c|}{ 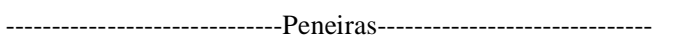 } & \multicolumn{2}{|c|}{-----Emerg. (\%)----- } & \multicolumn{2}{|c|}{----------IVE---------. } \\
\hline & P. 22 & P. 20 & P. 22 & P. 20 & $1^{\mathrm{a}} \mathrm{Av}$ & $2^{\underline{a}} \mathrm{Av}$. & $1^{\mathrm{a}} \mathrm{Av}$ & $2^{\underline{a}} \mathrm{Av}$ \\
\hline Amarelão & $98,02 \mathrm{cB}$ & $1,98 \mathrm{dA}$ & $99,32 \mathrm{aA}$ & $0,68 \mathrm{eB}$ & $93,5 \mathrm{bA}$ & $98 \mathrm{aA}$ & $6,47 \mathrm{bB}$ & $6,77 \mathrm{aA}$ \\
\hline Vinhedo & $99,48 \mathrm{bA}$ & $0,52 \mathrm{eB}$ & $98,19 \mathrm{bB}$ & $1,81 \mathrm{dA}$ & $98 \mathrm{aA}$ & $95,5 \mathrm{bA}$ & $6,77 \mathrm{aA}$ & $6,66 \mathrm{aA}$ \\
\hline Santo & $97,28 \mathrm{dA}$ & $2,72 \mathrm{cB}$ & $87,29 \mathrm{~dB}$ & $12,64 \mathrm{bA}$ & $96 \mathrm{bA}$ & $98,5 \mathrm{aA}$ & $6,50 \mathrm{bB}$ & $6,87 \mathrm{aA}$ \\
\hline Asteca & $99,18 \mathrm{bA}$ & $0,82 \mathrm{eA}$ & $98,51 \mathrm{bA}$ & $1,49 \mathrm{dA}$ & $98,5 \mathrm{aA}$ & $92,5 \mathrm{bA}$ & $6,88 \mathrm{aA}$ & $6,47 \mathrm{aB}$ \\
\hline B. Barra & $98,39 \mathrm{cA}$ & $1,61 \mathrm{dA}$ & $98,53 \mathrm{bA}$ & $1,47 \mathrm{dA}$ & $98,5 \mathrm{aA}$ & $93 \mathrm{bB}$ & $6,91 \mathrm{aA}$ & $6,19 \mathrm{bB}$ \\
\hline Coruja & $99,62 \mathrm{aA}$ & $0,38 \mathrm{fA}$ & $99,59 \mathrm{aA}$ & $0,41 \mathrm{eA}$ & $98 \mathrm{aA}$ & $99 \mathrm{aA}$ & $6,76 \mathrm{aA}$ & $6,64 \mathrm{aA}$ \\
\hline T. Doce & $92,29 \mathrm{eA}$ & $7,66 \mathrm{bB}$ & $85,31 \mathrm{~dB}$ & $14,63 \mathrm{bA}$ & $98 \mathrm{aA}$ & $93,5 \mathrm{bB}$ & $6,84 \mathrm{aA}$ & $6,55 \mathrm{aA}$ \\
\hline F. Rajado & $99,88 \mathrm{aA}$ & $0,12 \mathrm{fA}$ & $99,15 \mathrm{aB}$ & $0,21 \mathrm{eA}$ & $96 \mathrm{bA}$ & $93,5 \mathrm{bA}$ & $6,67 \mathrm{bA}$ & $6,56 \mathrm{aA}$ \\
\hline C. Anão & $99,50 \mathrm{bA}$ & $0,50 \mathrm{eB}$ & $98,4 \mathrm{bB}$ & $1,6 \mathrm{dA}$ & $97,5 \mathrm{aA}$ & $94 \mathrm{bB}$ & $6,75 \mathrm{aA}$ & $6,45 \mathrm{aB}$ \\
\hline Catingueiro & $99,84 \mathrm{aA}$ & $0,16 f A$ & $99,68 \mathrm{aA}$ & $0,32 \mathrm{eA}$ & $99 \mathrm{aA}$ & $98 \mathrm{aA}$ & $6,89 \mathrm{aA}$ & $6,79 \mathrm{aA}$ \\
\hline C. Crioulo & $99,52 \mathrm{aA}$ & $0,48 \mathrm{fB}$ & $97,64 \mathrm{bB}$ & $2,36 \mathrm{dA}$ & $99,5 \mathrm{aA}$ & $95,5 \mathrm{bB}$ & $6,91 \mathrm{aA}$ & $6,55 \mathrm{aB}$ \\
\hline Caiçara & $98,06 \mathrm{cA}$ & $1,94 \mathrm{dA}$ & $98,34 \mathrm{bA}$ & $1,66 \mathrm{dA}$ & $96 \mathrm{bA}$ & $94,5 \mathrm{bA}$ & $6,63 \mathrm{bA}$ & $6,60 \mathrm{aA}$ \\
\hline Amarelinho & $99,26 \mathrm{bA}$ & $0,74 \mathrm{eB}$ & $95,19 \mathrm{cB}$ & $4,77 \mathrm{cA}$ & $98 \mathrm{aA}$ & $99 \mathrm{aA}$ & $6,93 \mathrm{aA}$ & $6,61 \mathrm{aB}$ \\
\hline Tio João & $96,38 \mathrm{~dB}$ & $3,62 \mathrm{cA}$ & $97,86 \mathrm{bA}$ & $2,14 \mathrm{~dB}$ & $94 b A$ & $95,3 \mathrm{bA}$ & $6,55 \mathrm{bA}$ & $6,66 \mathrm{aA}$ \\
\hline M. Amarelo & $99,14 \mathrm{bA}$ & $0,86 \mathrm{eB}$ & $94,62 \mathrm{cB}$ & $5,38 \mathrm{cA}$ & $97,5 \mathrm{aA}$ & $95,5 \mathrm{bA}$ & $6,80 \mathrm{aA}$ & $6,50 \mathrm{aB}$ \\
\hline P. Vinhedo & $24,73 \mathrm{fA}$ & $51,74 \mathrm{aA}$ & $4,08 \mathrm{eB}$ & $52,91 \mathrm{aA}$ & $97,5 \mathrm{aA}$ & $91 \mathrm{bB}$ & $6,68 \mathrm{bA}$ & $6,08 \mathrm{bB}$ \\
\hline F. Campo & $99,03 \mathrm{bA}$ & $0,97 \mathrm{eB}$ & $94,79 \mathrm{cB}$ & $5,21 \mathrm{cA}$ & $99 \mathrm{aA}$ & $96,5 \mathrm{bA}$ & $6,82 \mathrm{aA}$ & $6,70 \mathrm{aA}$ \\
\hline $\mathrm{CV}(\%)$ & & & & 10,38 & & 5,20 & & 3,16 \\
\hline
\end{tabular}

Médias não seguidas pela mesma letra minúscula, na coluna, e maiúscula para a época de avaliação diferem entre si pelo teste Scott-Knott e $\mathrm{F}$, respectivamente, a $5 \%$ de probabilidade. 
classificado como semiárido), favorece o estabelecimento de sementes com menor umidade. Todas as amostras das diferentes variedades apresentaram percentual de umidade inferior a $13 \%$, variando de 10,50 a $11,88 \%$ e 8,68 a $12,18 \%$ de umidade antes e após o armazenamento, respectivamente (Tabela 1), favorecendo a preservação da qualidade fisiológica dessas sementes. Os efeitos da temperatura e da umidade sobre a conservação da qualidade das sementes armazenadas estão interrelacionados, por isso, quando as sementes são armazenadas com a umidade correta e embaladas adequadamente, os efeitos das altas temperaturas sobre o seu metabolismo serão menores (EMBRAPA, 2006).

O nível de qualidade fisiológica da semente pode ser avaliado por meio de dois parâmetros fundamentais: viabilidade e vigor. A viabilidade pode ser estimada pelo teste de germinação, que procura determinar a máxima germinação da semente em condições controladas favoráveis. O vigor representa os atributos não revelados pelo teste de germinação, determinados sob condições desfavoráveis (POPINIGIS, 1985).

O teste de germinação é conduzido sob condições consideradas ótimas de ambiente e, portanto, deve fornecer a germinação teoricamente máxima que se pode esperar de determinada amostra.
Essa informação é muito importante porque estabelece limite para o desempenho do lote de sementes após a semeadura (MARCOS FILHO, 2005). Das variedades analisadas, 16 alcançaram percentagens de germinação superiores a $90 \%$ no período anterior ao armazenamento (Tabela 3), sendo superior ao padrão mínimo exigido pela legislação $(85 \%)$. Quinze variedades não diferiram estatisticamente, tendo as variedades Santo e Amarelão apresentado menor germinação. Antes da armazenagem, apenas a variedade Amarelão apresentou germinação inferior ao padrão exigido, o que inviabilizaria a comercialização do respectivo lote como semente ou então este deveria ser rebeneficiado; contudo, após o armazenamento, todas as variedades atenderam às exigências da legislação. Dessa forma, a baixa germinação da variedade Amarelão no período anterior ao armazenamento pode estar relacionada a problemas específicos do lote amostrado, sendo verificado ainda que o armazenamento, de uma forma geral, apresentou-se eficiente na manutenção das qualidades físicas e fisiológicas dessas sementes. A avaliação da qualidade mínima para a comercialização é estabelecida pelos programas de certificação, mas é de fundamental importância que o agricultor desenvolva programa próprio de Controle Interno de Qualidade (CIQ).

Tabela 3 - Resultados de germinação (\%), primeira contagem de germinação (\%), índice de velocidade de germinação (IVG) em dois períodos de avaliação e infestação de sementes de milho crioulo.

\begin{tabular}{|c|c|c|c|c|c|c|c|}
\hline \multirow[t]{2}{*}{ Variedades } & \multicolumn{2}{|c|}{ Germinação (\%) } & \multicolumn{2}{|c|}{$1^{\text {a }}$ Contagem da Germinação (\%) } & \multicolumn{2}{|c|}{ IVG } & \multirow[t]{2}{*}{ Infestação (\%) } \\
\hline & $1^{\mathrm{a}} \mathrm{av}$ & $2^{\mathrm{a}}$ av. & $1^{\mathrm{a}} \mathrm{av}$ & $2^{\mathrm{a}} \mathrm{av}$ & $1^{\mathrm{a}}$ av. & $2^{\mathrm{a}}$ av. & \\
\hline Amarelão & $81 \mathrm{cB}$ & $97 \mathrm{aA}$ & $79 \mathrm{bB}$ & $96 \mathrm{aA}$ & $6,34 \mathrm{bA}$ & $6,15 \mathrm{aA}$ & $0,5 b$ \\
\hline Vinhedo & $99 \mathrm{aA}$ & $94 \mathrm{bA}$ & $98 \mathrm{aA}$ & $92 b B$ & $6,70 \mathrm{bA}$ & $6,13 \mathrm{aB}$ & $0,5 b$ \\
\hline Santo & $91 \mathrm{bA}$ & $96 \mathrm{aA}$ & $81 \mathrm{bB}$ & $95 \mathrm{bA}$ & $6,84 \mathrm{bA}$ & $5,98 \mathrm{aB}$ & $0,0 \mathrm{~b}$ \\
\hline Asteca & $98 \mathrm{aA}$ & $95 \mathrm{bA}$ & $96 \mathrm{aA}$ & $95 \mathrm{bA}$ & $7,27 \mathrm{bA}$ & $6,06 \mathrm{aB}$ & $0,5 b$ \\
\hline B. Barra & $100 \mathrm{aA}$ & $92 b B$ & $99 \mathrm{aA}$ & $92 \mathrm{bB}$ & $7,70 \mathrm{aA}$ & $5,82 \mathrm{aB}$ & $2,5 \mathrm{a}$ \\
\hline Coruja & $98 \mathrm{aA}$ & $99 \mathrm{aA}$ & $95 \mathrm{aA}$ & $99 \mathrm{aA}$ & $6,85 \mathrm{bA}$ & $6,25 \mathrm{aB}$ & $0,0 \mathrm{~b}$ \\
\hline T. Doce & $97 \mathrm{aA}$ & $96 \mathrm{bA}$ & $95 \mathrm{aA}$ & $96 \mathrm{aA}$ & $6,93 \mathrm{bA}$ & $6,06 \mathrm{aB}$ & $0,0 \mathrm{~b}$ \\
\hline F. Rajado & $97 \mathrm{aA}$ & $91 \mathrm{bB}$ & $91 \mathrm{aA}$ & $90 \mathrm{bA}$ & $6,99 \mathrm{bA}$ & $5,93 \mathrm{aB}$ & $0,0 \mathrm{~b}$ \\
\hline C. Anão & $100 \mathrm{aA}$ & $94 \mathrm{bA}$ & $97 \mathrm{aA}$ & $92 \mathrm{bA}$ & $6,46 \mathrm{bA}$ & $5,99 \mathrm{aB}$ & $7,5 \mathrm{a}$ \\
\hline Catingueiro & $98 \mathrm{aA}$ & $100 \mathrm{aA}$ & $97 \mathrm{aA}$ & $100 \mathrm{aA}$ & $7,36 \mathrm{bA}$ & $6,25 \mathrm{aB}$ & $0,5 \mathrm{~b}$ \\
\hline C. Crioulo & $100 \mathrm{aA}$ & $90 \mathrm{bB}$ & $99 \mathrm{aA}$ & $90 \mathrm{bB}$ & $7,10 \mathrm{bA}$ & $5,86 \mathrm{aB}$ & $0,5 b$ \\
\hline Caiçara & $97 \mathrm{aA}$ & $93 \mathrm{bA}$ & $97 \mathrm{aA}$ & $93 \mathrm{bA}$ & $7,10 \mathrm{bA}$ & $6,18 \mathrm{aB}$ & $1,0 \mathrm{~b}$ \\
\hline Amarelinho & $98 \mathrm{aA}$ & $98 \mathrm{aA}$ & $99 \mathrm{aA}$ & $98 \mathrm{aA}$ & $7,31 \mathrm{bA}$ & $6,09 \mathrm{aB}$ & $0,5 \mathrm{~b}$ \\
\hline Tio João & $97 \mathrm{aA}$ & $94 \mathrm{bA}$ & $97 \mathrm{aA}$ & $94 \mathrm{bA}$ & $7,21 \mathrm{bA}$ & $6,09 \mathrm{aB}$ & $4,0 \mathrm{a}$ \\
\hline M. Amarelo & $97 \mathrm{aA}$ & $95 \mathrm{bA}$ & $90 \mathrm{aA}$ & $95 \mathrm{bA}$ & $6,87 \mathrm{bA}$ & $6,09 \mathrm{aB}$ & $4,0 \mathrm{a}$ \\
\hline P. Vinhedo & $98 \mathrm{aA}$ & $93 \mathrm{bA}$ & $91 \mathrm{aA}$ & $93 \mathrm{bA}$ & $7,35 \mathrm{bA}$ & $6,09 \mathrm{aB}$ & $3,0 \mathrm{a}$ \\
\hline F. Campo & $100 \mathrm{aA}$ & $98 \mathrm{aA}$ & $100 \mathrm{aA}$ & $98 \mathrm{aA}$ & $7,79 \mathrm{aA}$ & $6,09 \mathrm{aB}$ & $1,5 \mathrm{~b}$ \\
\hline CV $(\%)$ & & 5,71 & & 6,94 & & 3,34 & 85,20 \\
\hline
\end{tabular}

*Médias não seguidas pela mesma letra minúscula, na coluna, e maiúscula para a época de avaliação diferem entre si pelo teste Scott-Knott e $\mathrm{F}$, respectivamente, a $5 \%$ de probabilidade. 
Os testes de vigor não são necessariamente efetuados para predizer o número exato de plântulas que emergirão ou sobreviverão no campo; no entanto, muitos dos resultados oriundos desses testes podem correlacionar-se com a porcentagem de emergência no campo e o potencial de armazenabilidade. Entre as amostras de sementes das variedades estudadas, a Flor do Campo e Branco da Barra apresentaram-se mais vigorosas, antes do período de armazenamento, destacando-se das demais pelo maior índice de velocidade de germinação. Após o armazenamento, todas as variedades apresentaram menor índice de velocidade de germinação (IVG) (Tabela 3), não se diferindo estatisticamente, com exceção da variedade Amarelão, reforçando a necessidade de melhor uniformização dos lotes dessa variedade.

As variedades Branco da Barra, Tupiniquim Doce, Cateto Crioulo e Pipoqueiro Vinhedo sofreram queda na taxa de emergência em campo na segunda época (Tabela 2). Todavia, em ambas as épocas, as taxas de emergência em campo foram satisfatórias, sendo superiores a $91 \%$. Pelo índice de velocidade de emergência (IVE), as variedades Branco da Barra, Tupiniquim Doce, Cateto Anão, Cateto Crioulo e Pipoqueiro Vinhedo apresentaram-se menos vigorosas na segunda época. As variedades Amarelão e Santo apresentaram-se menos vigorosas na primeira época de avaliação (Tabela 2).

Após o armazenamento das sementes, verificou-se a presença do gorgulho do milho (Sitophilus zeamais Mont.) (Coleoptera: Curculionídea), identificado de acordo com PRATES e FRATTINI (1976). As variedades Cateto Anão, Tio João e Mineiro Amarelo apresentaram infestação igual ou superior ao padrão máximo recomendado (3\%), e a variedade Pipoqueiro Vinhedo encontra-se no limite máximo permitido, sendo, portanto, necessário maior controle de pragas de grãos armazenados para essas sementes. Os baixos valores de sementes infestadas podem ser atribuídos não somente à eficiência dos tratamentos químicos, mas também ao fato de os teores de água das sementes durante o período de armazenamento estarem entre 8,68 e 12,18\%, valores considerados baixos para o desenvolvimento de insetos, sendo preservada a integridade física das sementes de milho, fato que concorda com os resultados obtidos por WEBER (2001). O método de armazenagem em garrafas PET permitiu uma melhor conservação das sementes no que diz respeito à qualidade fisiológica, umidade e infestação das sementes por insetos-praga. Esses resultados também foram observados por ANTONELLO et al. (2009), quando compararam variedades, tempo de armazenagem e métodos de embalagem. Para os mesmos autores, as embalagens PET permitiram uma melhor qualidade fisiológica, conservação de um baixo teor de umidade e, consequentemente, um menor índice de infestação por insetos devido ao baixo nível de oxigênio nas sementes de milho crioulo, em comparação com métodos tradicionais (sacaria).

\section{CONCLUSÃO}

Sementes das diferentes variedades de milho crioulo apresentaram alta qualidade física, fisiológica e sanitária antes e após o armazenamento em garrafas PET, apresentando valores acima dos padrões mínimos exigidos para comercialização. Porém, há necessidade de aperfeiçoar métodos que visem à uniformização das sementes em algumas variedades.

\section{REFERÊNCIAS}

AZEVEDO, M.R.Q.A. et al. Influência das embalagens e condições de armazenamento no vigor de sementes de gergelim. Revista Brasileira de Engenharia Agrícola e Ambiental, Campina Grande, PB, v.7, n.3, p.519-524, 2003. Diponível em: <http:// www. scielo.br/scielo.php? script $=$ sci_arttext\&pid $=$ S14 15 43662003000300019>. Acesso em: 15/04/2010. doi: 10.1590/ S1415-43662003000300019.

ANTONELLO, L.M. et al. Influência do tipo de embalagem na qualidade fisiológica de sementes de milho crioulo. Revista Brasileira de Sementes, Londrina, PR, v.31, n.4, p.75-86, 2009. Disponível em: <http://www.scielo.br/scielo.php?pid=S010131222009000400009\&script=sci_arttext $>$. Acesso: 18 jun. 2010. doi: 10.1590/S0101-31222009000400009.

BAUDET, L.; MISRA, M. Atributos de qualidade de sementes de milho beneficiadas em mesa de gravidade. Revista Brasileira de Sementes, Brasília, v.13, n.2, p.91-97, 1991.

BRASIL. Ministério da Agricultura e reforma Agrária. Regras para análises de sementes. Brasília: SNDA/DNDV/CLAV, 2009. 398p.

CAMPOS, S.R.F. et al. Aspectos legais da produção e da comercialização de sementes. Informe Agropecuário, Belo Horizonte, v.27, n.232, p.15-21, 2006

CARVALHO, N.M.; NAKAGAWA, J. Sementes: ciência, tecnologia e produção. Jaboticabal: Funep, 2000. 588p.

COSTA, J.G.; CAMPOS, I.S. Recomendações básicas para a produção de sementes de milho no nível da pequena propriedade rural. Acre: EMBRAPA, 1997. (Instrução técnica, n.4).

EMPRESA BRASILEIRA DE PESQUISA AGROPECUÁRIA EMBRAPA. Produção de sementes no âmbito da agricultura familiar: unidades coletivas de multiplicação de sementes: procedimentos e critérios para organização. Brasília, DF.: EMBRAPA Transferência de Tecnologia, 2006. 26p. (Convênio 3218 Embrapa/SNT MDA Fome Zero). 
KIKUTI, A.L.P. et al. Desempenho de sementes de milho em relação à sua localização na espiga. Ciência Agrotécnica, Lavras. v.27, n.4, p.765-770, 2003.

Legislação Brasileira sobre sementes e mudas: Lei n. 10.711, de 5 de agosto de 2003 e Decreto n. 5.153, de 23 de julho de 2004. Brasília, 2004. 121p.

MAGUIRE, J.D. Speed of germination-aid in seletion and evaluation for seedlig emergence and vigor. Crop Science, Madison, v.2, n.1, p.176-177, 1962.

MARCOS FILHO, J. Fisiologia de sementes de plantas cultivadas. Piracicaba: Fealq, 2005. 495p.

MARTINELLI-SENEME, A. et al. Efeito da forma e do tamanho da semente na produtividade do milho cultivar AL34. Revista Brasileira de Sementes, Brasília, v.23, n.1, p.40-47, 2001.

MENEGUETTI, G.A. et al. Milho crioulo: tecnologia viável e sustentável. Agroecologia e Desenvolvimento Rural Sustentável, Porto Alegre, v.3, n.1, p.12-17, 2002.

POPINIGIS, F. Fisiologia da semente. 2.ed. Brasília: PAX, 1985. 289p.
PRATES, H.S.; FRATTINI, J.A. Principais pragas dos grãos armazenados e recomendação para seu controle. Campinas: CATI, 1976. 26p. (Boletim Técnico, 89).

SATO, O.; CICERO, S.M. Selection of corn (Zea mays L.) ears and seed thrashing: I - effect on physical quality and insect infestation. Science Agricola, Piracicaba, v.49, n.spe, p.93-101, 1992. Disponível em: <http://www.scielo.br/scielo.php?script=sci_arttext\&pid=S010390161992000400013>. Acesso em: 22 fev. 2010. doi: 10.1590/ S0103-90161992000400013.

SCHUCH, L.O.B.; PESKE, S.T. Falhas e duplos na produtividade. Seeds news, ano XII, n.6 2008 (Reportagem da capa). Disponível em: <http://www.seednews.inf.br/portugues/seed126/ artigocapa126.shtml>. Acesso em: 10 nov. 2008.

TRAVERSO, J.E. Colecta, conservation y utilizacion de los recursos de interes forrajero nativo y naturalizado. In: PROCISUR (Ed.) Dialogo LVI - Los recursos fitogenetico del genero bromus em el cono sur. Bagé, RS, 2001. p.1928 .

WEBER, E.A. Armazenagem Agrícola. Guaíba: Agropecuária, 2001. 333p. 